\title{
Evaluation of Role of Facet Joints in Persistent Low Back Pain in Obesity: A Controlled, Prospective, Comparative Evaluation
}

\author{
Laxmaiah Manchikanti, MD*, Vidyasagar Pampati, MSc ${ }^{* *}$, Vijay Singh, MD\#, Carla Beyer, RN\#, Kim \\ Damron, RN"\#, and Bert Fellows, MA ${ }^{\circ}$
}

Chronic low back pain and obesity are two common medical conditions. Obesity has been associated with symptoms such as adverse fat distribution and multiple secondary disorders, including low back pain. Obesity is defined as being $30 \%$ over ideal weight, which influences normal body mechanics as well as recovery from an injury.

Facet joints have been described as contributing to a significant proportion of patients suffering with persistent or chronic low back pain, variably from $15 \%$ to $45 \%$. Since an obese patient is at a higher risk of disability compared to a patient with normal weight, obesity has been described as a confounding factor in persistent low back pain. This study included 100 patients, with 50 patients in Group I who were of normal weight and 50 patients in group II who were obese, by random allocation. Facet joints were investigated with diagnostic blocks using lidocaine $1 \%$ initially, followed by bupivacaine $0.25 \%$. The results showed that the prevalence rate of facet joint pain in chronic low back pain in Group I or nonobese patients was $36 \%$, in contrast to $40 \%$ in Group II, or the obese patient group, with no significant differences among the two groups. The study also showed a falsepositive rate of $39 \%$ in the total sample, or $44 \%$ in Group I nonobese patients and $33 \%$ in Group II, or obese patients.

It is concluded that the prevalence of lumbar facet joint mediated pain of $40 \%$ in obese patients and $36 \%$ in patients of normal weight with a false-positive rate of $33 \%$ in obese patients and $44 \%$ in nonobese patients is similar to the results of multiple previous studies concluding that facet joint mediated pain is a common occurrence in obese patients; however, the incidence of facet joint mediated pain is similar in obese patients and nonobese patients.

Keywords: Obesity, persistent low back pain, facet joint mediated pain, comparative local anesthetic blocks, falsepositive rate, facet joint nerve blocks
Chronic low back pain and obesity are important clinical, social, economic and public health problems affecting the population indiscriminately (1-14). Obesity has been associated with symptoms such as adverse fat distribution; and secondary disorders including coronary artery disease, stroke, noninsulin-dependent diabetes mellitus, cancer, and low back pain. There are several hypotheses relating to a link between obesity and low back pain. Increased mechanical demands resulting from obesity have been suspected of causing low back pain through excessive wear and tear, and it has been suggested that metabolic factors

From Pain Management Center of Paducah, Paducah, Kentucky and Pain Diagnostic Associates, Niagara, Wisconsin. *Medical Director, **statistician, ${ }^{*}$ clinical coordinators, and ${ }^{\Omega}$ psychologist at the Pain Management Center of Paducah. \# Dr. Singh is Medical Director of Pain Diagnostic Associates. Address correspondence: Laxmaiah Manchikanti, MD, 2831 Lone Oak Road, Paducah, Kentucky 42003. E-mail: drm@ asipp.org associated with obesity may be detrimental (15-23). Obesity, defined as being $30 \%$ over ideal weight, influences normal body mechanics by making it more difficult to sit, stand, and walk and increases the time required to recover from an injury. Fatty tissue is a stress on the body even when a person is not injured, as it decreases the blood flow carrying nutrients for healing to the injured area. As it is presumed that too much fat is associated with loss of endurance, it is also presumed that obesity also makes rehabilitation more difficult for the low back injury patient since poor endurance and cardiovascular fitness may hinder full participation in therapy (22). Thus, some consider obesity as a strong, contributing factor of low back pain (16, 24$29)$; whereas others consider it a possible, but not a particularly strong, contributing factor of low back pain (30); whereas still others do not think it is a risk factor of low back pain $(31,32)$. In addition, it also has been postulated that obesity may be a marker $(15)$ or a confounder $(17,19)$ for some of the factors that are a true cause of low back pain. Thus, obesity is only considered as a possible risk factor of low back pain (1). 
However, a significant number of patients, whether obese, overweight, or normal weight, suffer with facet joint mediated chronic low back pain. Well-controlled studies have demonstrated the prevalence of persistent low back pain secondary to the involvement of lumbosacral facet joints to be variable, from $15 \%$ to $45 \%$ (33-37). Even though evidence is lacking for the diagnosis of the so-called lumbar facet syndrome (33-41), a preponderance of evidence supports the existence of lumbar facet joint pain (33-50). Even then, there are a few detractors questioning the existence of facet joint mediated pain itself (51-55). It appears that an obese patient is at an even higher risk of disability compared to a patient with normal weight, with obesity as a confounding factor in persistent low back pain, not only with maintenance of functional status but also with rehabilitation.

Since there is no controlled or uncontrolled evidence showing the presence or the lack thereof of facet joint mediated pain in obese patients, this study was designed to evaluate the prevalence of facet joint mediated pain in obese patients compared to patients of normal weight.

\section{METHODS}

The study population consisted of 100 patients seen at one private pain management practice in a nonuniversity setting. Patients were divided into two groups. Group I was of normal weight, and Group II was obese. Patients were randomly allocated to one of the groups from the pool of patients who had a chief complaint of low back pain. All patients presented for pain management. Patients younger than 18 years or older than 90 years, those who were overweight but not obese with a body mass index (BMI) of 25 to 29.9 , those who exhibited neurological deficits, those who had pain for less than 6 months or had undergone neural blockade in the past were excluded. Evaluation included completion of a standard pain-management questionnaire, history, physical examination, and evaluation of the results of all procedures and investigations. The nature of the study and the potential hazards of the procedures were explained to all patients, all of whom consented to participate. Facet joints were investigated with diagnostic blocks using lidocaine $1 \%$ initially followed by bupivacaine $0.25 \%$, at least 2 weeks apart. The blocks were performed on the ipsilateral side in patients with unilateral pain, or bilaterally in patients with bilateral or axial pain.

The blocks were performed by one investigator in an operating room equipped with an image intensifier, with pa- tients in the prone position. Intravenous access and mild sedation with midazolam were carried out in most cases. Blocks were performed under intermittent fluoroscopic visualization at each of the medial branches at L1-4 and L5 dorsal ramus, using a 22-gauge, 3.5- or 5-inch spinal needle. Each nerve was infiltrated with 0.4 to $0.6 \mathrm{~mL}$ of either $1 \%$ lidocaine or $0.25 \%$ bupivacaine with or without adjuvants. A definite response was defined as relief of at least $75 \%$ in the symptomatic area. Following each block, the patient was examined and painful movements were performed. Confirmatory blocks using bupivacaine $0.25 \%$ were performed at the same levels as the first injection if definite relief was obtained. The response to bupivacaine blocks was evaluated after at least 2 weeks following the second injection, with pain relief lasting longer than the duration of the lidocaine blocks for at least 3 hours. Any other response was considered as negative.

Data were recorded on a database using Microsoft ${ }^{\circledR}$ Access ${ }^{\circledR}(36)$; the SPSS Version 9.0 statistical package was used to generate the frequency tables and the chi-squared statistic was used to test the significance difference between groups. Fisher's Exact Test was used wherever the expected value was less than five. Student's t test was used to test mean difference between groups. A BMI of 25 to 29.9 was considered as overweight, while a BMI of 30 or over was considered as obese. Results were considered statistically significant if the $P$ value was less than 0.05 .

\section{RESULTS}

\section{Patient Characteristics}

Of the 100 patients included in the study, $39 \%$ of the patients were drawn from the county of the practice location, and $61 \%$ were drawn from various other counties within the state and surrounding states. Twenty nine percent of the patients were evaluated with unilateral blocks; $71 \%$ were evaluated with bilateral blocks, with no significant difference noted among the groups.

As shown in Table 1, overall gender distribution was $37 \%$ men and $63 \%$ women, with no significant difference among the groups $(\mathrm{P}=0.107)$. Height evaluation also showed no significant differences among groups. However, mean weights showed significant difference among groups $(\mathrm{P}=0.000)$. Mode of onset of low back pain was determined as traumatic in $50 \%$ of the patients in Group I and $60 \%$ of the patients in Group II, with no significant difference noted among groups $(\mathrm{P}=0.494)$. History of occupa- 
Table 1. Patient Characteristics

\begin{tabular}{|c|c|c|c|}
\hline & & $\begin{array}{c}\text { Group I } \\
\text { Normal weight }\end{array}$ & $\begin{array}{l}\text { Group II } \\
\text { Obesity }\end{array}$ \\
\hline \multicolumn{2}{|l|}{ Number of patients } & $\mathrm{N}=50$ & $\mathrm{~N}=50$ \\
\hline \multirow{2}{*}{ Gender } & Male & $30 \%(15)$ & $44 \%(22)$ \\
\hline & Female & $70 \%(35)$ & $56 \%(28)$ \\
\hline \multirow{2}{*}{ Age (yrs.) } & Range & $22-82$ & $22-81$ \\
\hline & Mean \pm SEM & $45.3 \pm 1.94$ & $45.1 \pm 1.84$ \\
\hline \multirow{2}{*}{ Weight (lbs.) } & Range & $98-180$ & $155-350$ \\
\hline & Mean \pm SEM & $136.4 \pm 2.72$ & $236.5^{*} \pm 6.66$ \\
\hline \multirow{2}{*}{ Height (inches) } & Range & $61-73$ & $51-76$ \\
\hline & Mean \pm SEM & $66.7 \pm 0.44$ & $66.9 \pm 0.67$ \\
\hline \multicolumn{2}{|l|}{ Body mass index } & $21.4 \pm 0.29$ & $36.9 \pm 0.86$ \\
\hline \multirow{4}{*}{ Mode of onset of pain } & Occupational & $18 \%(9)$ & $30 \%(15)$ \\
\hline & MVA & $16 \%(8)$ & $18 \%(9)$ \\
\hline & Nonoccupational & $16 \%(8)$ & $12 \%(6)$ \\
\hline & Gradual onset & $50 \%(25)$ & $40 \%(20)$ \\
\hline \multirow{4}{*}{$\begin{array}{l}\text { Duration of pain } \\
\text { (years.) }\end{array}$} & Range & $0.5-32$ & $0.5-34$ \\
\hline & $<1$ & $20 \%(10)$ & $20 \%(10)$ \\
\hline & $1-4$ & $36 \%(18)$ & $26 \%(13)$ \\
\hline & $>4$ & $44 \%(22)$ & $54 \%(27)$ \\
\hline \multicolumn{2}{|l|}{ Surgical intervention } & $28 \%(14)$ & $30 \%(15)$ \\
\hline \multirow{4}{*}{ Pain ratio } & Back pain only & $14 \%(7)$ & $6 \%(3)$ \\
\hline & Back worse than leg & $48 \%(24)$ & $48 \%(24)$ \\
\hline & Back and leg pain equal & $32 \%(16)$ & $30 \%(15)$ \\
\hline & Leg pain worse than back & $6 \%(3)$ & $16 \%(8)$ \\
\hline
\end{tabular}

tional, nonoccupational, or motor vehicle injuries was included in the traumatic group. Duration of pain in years ranged from 1 to 30 years in both groups, with no significant differences $(\mathrm{P}=0.518)$. No significant differences were noted in the distribution of pain, either unilateral, bilateral, axial, or only back pain, back pain worse than leg pain, back pain and leg pain equal, or leg pain worse than back pain $(\mathrm{P}=0.272)$. Patients with a history of one or more surgical interventions constituted $28 \%$ of Group I and $30 \%$ of Group II, with no significant difference (P $=0.826)$.

\section{Injection Characteristics}

All patients underwent single blocks with lidocaine, with or without adjuvants. Thirty two, or $64 \%$ of the patients in Group I, and thirty, or $60 \%$ of the patients in Group II, reported a definite response to screening blocks with lidocaine. Confirmatory blocks with bupivacaine were performed in all patients who were lidocaine positive, with $36 \%$ of the total sample, or $56 \%$ of the lidocaine positive group, reporting a definite response, with improvement in pain in Group I, in contrast with $40 \%$ of the total sample, or $67 \%$ of the lidocaine positive, in Group II (Table 2). 
Table 2. Comparison of the results of single blocks (lidocanie) and double blocks (lidocaine and bupivacaine)

\begin{tabular}{|c|c|c|c|c|}
\hline \multirow[b]{3}{*}{ Single block } & \multicolumn{2}{|c|}{$\begin{array}{c}\text { Group I } \\
\text { Normal weight }\end{array}$} & \multicolumn{2}{|c|}{$\begin{array}{l}\text { Group II } \\
\text { Obesity }\end{array}$} \\
\hline & \multicolumn{2}{|c|}{ Double Blocks } & \multicolumn{2}{|c|}{ Double Blocks } \\
\hline & Positive & Negative & Positive & Negative \\
\hline Positive & 18 & 14 & 20 & 10 \\
\hline Negative & & 18 & & 20 \\
\hline Prevalence & \multicolumn{2}{|c|}{$36 \%$} & \multicolumn{2}{|c|}{$40 \%$} \\
\hline False positive rate & \multicolumn{2}{|c|}{$44 \%$} & \multicolumn{2}{|c|}{$33 \%$} \\
\hline Specificity & \multicolumn{2}{|c|}{$56 \%$} & \multicolumn{2}{|c|}{$67 \%$} \\
\hline
\end{tabular}

\section{Prevalence}

All patients who underwent double blocks with a definite response were considered as positive, yielding a prevalence rate of facet joint pain in chronic low back pain in Group I of $36 \%$, in contrast to $40 \%$ in Group II. There were significant differences noted among the groups with regard to the prevalence of low back pain $(\mathrm{P}=0.680)$.

\section{Specificity}

The specificity was calculated by determining the proportion of patients who had no response to lidocaine. Using the response to double blocks as a criterion standard, the specificity of lidocaine was found, on average, to be only $61 \%$, with a resultant false-positive rate of $39 \%$ (Table 2). No differences were noted among the groups $(\mathrm{P}=0.400)$.

\section{DISCUSSION}

Obesity is a serious medical problem that is increasing in prevalence, affecting millions and of great interest to the public; with low back pain (1-12), for which the burden of obesity has been articulated, investigators have used indicators such as prevalence $(11,12)$, economic cost (13), and association with risk factors and diseases (14). Allison et al (11) estimated the number of annual deaths attributable to obesity among US adults as approximately 280,000 based on hazard ratios. In addition to death, obesity also has been associated with multiple medical disorders including low back pain. There are several hypotheses that link obesity and low back pain. Leboeuf-Yde (23) conducted a systematic review of the epidemiologic literature to establish whether body rate is truly associated with low back pain and whether the link may be causal. She reviewed 56 original research reports, reporting on 65 studies published between 1965 and 1997, for the frequency of positive associations between body weight and low back pain and examined the presence of positive findings in relation to several study characteristics. The results of this review were that $32 \%$ of all the studies reported statistically significant positive weak association between body weight and low back pain. Thus, the association between body weight and low back pain, when present in large, general population-based studies, was weak, with a weight ratio of less than two. However, Lean et al (29), in a crosssectional study of approximately 13,000 (6,000 men and 7,000 women), aged 20 to 59 years, reported that chronic low back pain of more than 12 weeks per year was $14 \%$ in men with a normal waist circumference, compared to $20 \%$ to $21 \%$ with moderately and significantly larger waist circumference. Similarly, Han et al (56) evaluating the prevalence of low back pain in associations with body fatness, fat distribution, and height, evaluated 5,887 men and 7,018 women aged 20 to 60 years. They reported that women who are overweight or have a large waist have a significantly increased likelihood of low back pain. Obesity in relation to herniated lumbar intervertebral discs also showed conflicting results $(15,18,56)$. Han et al $(56)$ also concluded that intervertebral disc herniation symptoms were more common in women who were overweight or had a larger waist circumference, whereas others also have found significant correlation between height and heavy body mass with intervertebral disc herniation $(15,18)$. O'Neill et al (57), in a population-based survey, reported that increasing BMI was associated with more frequent 
osteophytes at both the dorsal and lumbar spine, even though the relationship was stronger at the dorsal spine.

The structures responsible for low back and lower extremity pain include facet joints, intervertebral discs, spinal cord, nerve roots, vertebrae, ligaments and muscles. Facet joints have been implicated as responsible for low back and lower extremity pain in $15 \%$ to $45 \%$ of the patients suffering with chronic low back pain, utilizing controlled diagnostic blocks (33-39). Thus, a preponderance of evidence supports the existence of lumbar facet joint pain (33-50). The diagnosis of the so-called lumbar facet syndrome depends on a clinical presentation with mechanical low back pain described by the patient as mainly in the low back with radiation to the buttocks and upper posterior thigh. Some investigators have attempted to identify facet syndrome and predictors of outcomes of facet joint injections, which has been rather futile. The results of most studies failed to show a correlation between radiologic imaging findings, clinical examination, and the controlled diagnostic blocks. Hence, diagnostic blocks appear to be the only gold standard available now for diagnosis of facet joint mediated pain. The rationale for facet joint blocks is based on the observation that, if a particular joint is determined to be the source of pain generation, long-term relief can be sought by directing therapeutic interventions at that joint. Thus, in managing low back pain, local anesthetic injection to the facet joints or interruption of the nerves applied to the facet joints has been categorically accepted as the standard for diagnosis of facet joint mediated pain. Instead of placebo-controlled diagnostic facet joint blocks, a convenient control is the use of comparative local anesthetic blocks, in which on two separate occasions, the same structure is anesthetized, but using local anesthetics with different durations of action. One of the drawbacks of local anesthetic controlled blocks is that these may not be implementable for intra-articular blocks because it is not known whether the placement of local anesthetic in a relatively avascular environment such as a joint space affects its expected duration of action, and leakage of anesthetic from the joint capsule onto the exiting nerve root may give a false-positive response. However, comparative local anesthetic diagnostic blocks are implemented readily for facet joint nerve blocks. With facet joint nerve blocks, the use of comparative local anesthetic blocks has been evaluated and found to be valid against challenge with placebo (39). Further, a diagnosis cannot be rendered reliably on the basis of a single block because the false-positive rates are seen in as many as $41 \%$ of the patients (33-39). Thus, it appears that controlled diagnostic blocks with comparative local anesthetics are, not only a requirement, but also a prudent medical practice essentially in every case. Unfortunately, in spite of comparative local anesthetic blocks ruling out false positives, etc., they appear to be reliable only $85 \%$ of the time (39).

The prevalence of lumbar facet joint mediated pain of $40 \%$ in obese patients and $36 \%$ in patients of normal weight established in this study is similar to that of various previous studies. The criteria adapted for the diagnosis of lumbar facet joint pain in this study are as stringent as proposed by others in the literature. A false-positive rate of $39 \%$ is also in agreement with a multitude of previous studies.

Thus, the results of this study are important, as facet joint mediated pain is a significant and real problem in obese individuals. Proper diagnosis and subsequent treatment can alleviate a multitude of problems related to low back pain in obese patients with appropriate rehabilitation.

\section{CONCLUSION}

This study has demonstrated the prevalence of low back pain secondary to facet joint involvement as $40 \%$ in obese patients and $36 \%$ in patients with normal weight. A falsepositive rate of $33 \%$ in obese patients and $44 \%$ in patients of normal weight was reported with controlled, double, diagnostic blocks in this study. Hence, we conclude that, even though obesity and low back pain are commonly seen both in combination and separately, facet joint mediated pain in persistent low back pain in obese patients appears to be similar to that in nonobese patients. Thus, the facet joints contribute to persistent low back pain in $33 \%$ of the obese patients and $44 \%$ of patients with normal weight. Hence, facet joints are an important cause of persistent low back pain in obese as well as normal patients.

\section{ACKNOWLEDGMENTS}

We would like to thank Marla K. Neihoff and Lori A. Rose, medical records coordinators, for their assistance in collection of data. We would also like to thank Denise Pratt and Tonie Hatton, transcriptionists, for their assistance with transcription of the manuscript.

\section{REFERENCES}

1. Manchikanti L. Epidemiology of low back pain. Pain Physician 2000; 3:167-192.

2. Spitzer WO, Leblanc FE, Dupuis M (eds). Quebec Task Force on Spinal Disorders. Scientific approach 
to the assessment and management of activity-related spinal disorders: A monograph for clinicians. Spine 1987; (suppl) 12:1-59.

3. Deyo RA, Tsui-Wu YJ. Descriptive epidemiology of low back pain and its related medical care in the United States. Spine 1987; 12:264-268.

4. Lawrence RC, Helmick CG, Arnett FC. Estimates of the prevalence of arthritis and selected musculoskeletal disorders in the United States. Arthritis \& Rheumatism 1998; 41:778-799.

5. Gureje O, Von Korff M, Simon GE et al. Persistent pain and well being. A World Health Organization Study in Primary Care. JAMA 1998; 280:147-151.

6. Loney PL, Stratford PW. The prevalence of low back pain in adults. A methodological review of the literature. Physical Therapy 1999; 79:384-396.

7. Leboeuf-Yde C, Lauritsen JM. The prevalence of low back pain in the literature. A structured review of 26 Nordic studies from 1954 to 1993. Spine 1995; 20:2112-2118.

8. Bressler HB, Keyes WJ, Rochon PA et al. The prevalence of low back pain in the elderly. A systematic review of the literature. Spine 1999; 24:1813-1819.

9. Duggleby T, Kumar S. Epidemiology of juvenile low back pain. A review. Disabil Rehabil 1997;19:505512.

10. Waddell G. The back pain revolution. Churchill Livingston, Edinburgh, 1998, pp 85-101.

11. Allison DB, Fontaine KR, Manson JE et al. Annual deaths attributable to obesity in the United States. JAMA 1999; 282:1530-1538.

12. Flegal KM, Carroll MD, Kuczmarski RJ et al. Overweight and obesity in the United States. Prevalence and trends. 1960-1994. Int JObes Relat Metab Disord 1998; 22:39-47.

13. Allison DB, Zannolli R, Narayan KM. The direct health care costs of obesity in the United States. AmJ Public Health 1999; 89:1194-1199.

14. Allison DB, Pi-Sunyer FX. Obesity treatment. Examining the premises. Endocrinol Pract 1995; 1:353-364.

15. Heliövaara M. Body height, obesity, and risk of herniated lumbar intervertebral disc. Spine 1987; 12:469472.

16. Kelsey JL. An epidemiological study of the relationship between occupations and acute herniated lumbar intervertebral discs. Int J Epidemiol 1975;4:197-205.

17. Aro S, Leino P. Overweight and musculoskeletal morbidity. A ten-year follow-up. Int J Obesity 1985 ; 9:267-275.

18. Böstman OM. Body mass index and height in patients requiring surgery for lumbar intervertebral disc herniation. Spine 1993; 18:851-854.

19. Deyo RA, Bass JE. Lifestyle and low back pain. The influence of smoking and obesity. Spine 1989;14:501506.
20. Pope MH, Bevins T, Wilder DG et al. The relationship between anthropometric, postural, muscular, and mobility characteristics of males ages 18-55. Spine 1985; 10:644-648.

21. Wright D, Barrow S, Fisher AD et al. Influence of physical, psychological, and behavioral factors on consultations for back pain. BrJRheumatol 1995;34:156161.

22. Smith N. Nutrition and the athlete. Orthop Clin North Am 1983; 14:387-396.

23. Leboeuf-Yde C. Body weight and low back pain. A systematic literature review of 56 journal articles reporting on 65 epidemiologic studies. Spine 2000; 25:226-237.

24. Bergenudd H, Nilsson B, Uden A et al. Bone mineral content, gender, body posture, and build in relation to back pain in middle age. Spine 1989; 14:577-579.

25. White A, Panjabi M. Clinical biomechanics of the spine. Philadelphia, JB Lippincott, 1978, pp 329-336.

26. Pope M, Rosen J, Wilder D et al. The relation between biomechanical and psychological factors in patients with low-back pain. Spine 1980; 5:173-178.

27. Hanningan W, Elwood P, Henderson JP et al. Surgical results in obese patients with sciatica. Neurosurgery 1987; 20:896-899.

28. Weir B. Prospective study of 100 lumbosacral discectomies. J Neurosurg 1979; 50:283-289.

29. Lean MEJ, Han TS, Seidell JC. Impairment of health and quality of life in people with large waist circumference. Lancet 1998; 351:853-856.

30. Pope MH. Risk indicators in low back pain. Ann Med 1989; 21:387-392.

31. Hildebrandt VH. A review of epidemiological research on risk factors of low back pain. In Buckle PE (ed). Musculoskeletal Disorders at Work . London, Taylor and Francis, 1987; pp 9-16.

32. Kelsey JL, Hochberg MC. Epidemiology of chronic musculoskeletal disorders. Ann Rev Public Health 1988; 9:379-401.

33. Schwarzer AC, Aprill CN, Derby R et al. Clinical features of patients with pain stemming from the lumbar zygapophysial joints. Is the lumbar facet syndrome a clinical entity? Spine 1994; 19:1132-1137.

34. Manchikanti L, Pampati RR, Fellows B et al. The diagnostic validity and therapeutic value of medial branch blocks with or without adjuvants. Cur Rev Pain 2000; 4:337-344.

35. Schwarzer AC, Wang S, Bogduk N et al. Prevalence and clinical features of lumbar zygapophysial joint pain. A study in an Australian population with chronic low back pain. Am Rheum Dis 1995; 54:100-106.

36. Manchikanti L, Pampati VS, Fellows B et al. The inability of the clinical picture to characterize pain from facet joints. Pain Physician 2000;3:158-166.

37. Manchikanti L, Pampati VS, Pakanati RR et al. Prevalence of facet joint pain in chronic low back pain. 
Pain Physician 1999; 2:59-64.

38. Manchikanti L. Facet joint pain and the role of neural blockade in its management. Curr Rev Pain 1999; 3:348-358.

39. Bogduk N. International spinal injection society guidelines for the performance of spinal injection procedures. Part 1. Zygapophysial joint blocks. Clin J Pain 1997; 13:285-302.

40. Dreyfuss PH, Dreyer SJ, Herring SA. Contemporary concepts in spine care. Lumbar zygapophysial (facet) joint injections. Spine 1995; 20:2040-2047.

41. Schwarzer AC, Derby R, Aprill CN et al. Pain from the lumbar zygapophysial joint. A test of two models. J Spinal Disord 1994; 7:331-336.

42. Mooney V, Robertson J. The facet syndrome. Clin Orthop 1976, 115:149-156.

43. McCall IW, Park WM, O'Brien JP. Induced pain referral from posterior elements in normal subjects. Spine 1979; 4:441-446.

44. Marks R. Distribution of pain provoked from lumbar facet joints and related structures during diagnostic spinal infiltration. Pain 1989; 39:37-40.

45. Fukui S, Ohseto K, Shiotani M et al. Distribution of referral pain from the lumbar zygapophyseal joints and dorsal rami. Clin J Pain 1997; 13:303-307.

46. Carette S, Marcoux S, Truchon R et al. A controlled trial of corticosteroid injections into facet joints for chronic low back pain. N Engl J Med 1991; 325:10021007.

47. Lippitt AB. The facet joint and its role in spine pain. Management with facet joint injections. Spine 1984; 9:746-750.
48. Lilius G, Laasonen EM, Myllynen P et al. Lumbar facet joint syndrome. A randomized clinical trial. $J$ Bone Joint Surg (Br) 1989; 71:681-684.

49. Lynch MC, Taylor JF. Facet joint injection for low back pain. A clinical study. JBone Joint Surg (Br) 1986; 68:138-141.

50. Mironer YE, Somerville JJ. Protocol for diagnosis and treatment of facet joint pain syndrome. A modified three-step approach. Pain Digest 1999; 9:188-190.

51. Jackson RP, Jacobs RR, Montesano PX. Facet joint injection in low back pain. A prospective study. Spine 1988; 13:966-971.

52. Deyo RA. Fads in the treatment of low back pain. $N$ Engl J Med 1991; 325:1038-1040.

53. Jackson RP. The facet syndrome. Myth or reality? Clin Orthop 1992; 279:110-121.

54. Nachemson AL. Newest knowledge of low back pain. A critical look. Clin Orthop 1992; 279:8-20.

55. Nachemson AL, Vingard E. Assessment of patients with neck and back pain: A best-evidence synthesis. In Nachemson AL, Jonsson E (eds). Neck and back pain. The scientific evidence of causes, diagnosis and treatment . Lippincott Williams \& Wilkins, New York, 2000, pp 189-236.

56. Han TS, Schouten JS, Lean ME et al. The prevalence of low back pain and associations with body fatness, fat distribution, and height. Int JObes Relat Metab Disord 1997; 21:600-607.

57. O'Neill TW, McCloskey EV, Kanis JA et al. The distribution, determinants, and clinical correlates of vertebral osteophytosis. A population based survey. $J$ Rheumatol 1999; 26:842-848. 